\title{
Trends in the differences between homogenized ground surface temperature and surface air temperature in China during 1961-2016 and its possible causes
}

\author{
Xiaohui Shi $^{1}$ (D) Jinqiu Chen ${ }^{1}$ \\ Received: 3 August 2020 / Accepted: 8 January 2021 / Published online: 18 January 2021 \\ (C) The Author(s) 2021
}

\begin{abstract}
Based on the latest series of homogenized ground surface temperature (GST) and surface air temperature (SAT) data for China, this study performed a detailed analysis of the trend of the differences between the two homogenized series in 1961-2016. The differences, referred to as surface-air temperature differences (SATDs) in this study, were separately averaged by month, season, and year. The long-term and spatial changes in the trends of SATDs were investigated. Moreover, interdecadal trend breakpoints were identified to understand the characteristics of trends in fluctuation. The possible influences of precipitation, Pacific Decadal Oscillation (PDO), and global warming on SATDs were also analyzed. The results showed that during the 12 months of a year, only three months, March, April, and May, exhibited increasing trends of station-averaged, monthly mean SATDs while the other nine months exhibited decreasing trends. In addition, the station-averaged annual and seasonal mean SATDs of summer, autumn, and winter all showed significant decreasing trends, while the spring mean SATDs showed a significant increasing trend. The spatial distribution pattern of the linear trends of monthly, seasonal, and annual SATDs in meteorological stations indicated that SATDs had more obviously increasing trends in the northern regions than the southern regions of China. The trends of stationaveraged monthly mean SATDs (except for April) and station-averaged seasonal and annual mean SATDs experienced interdecadal breakpoints, fully indicative of obvious interdecadal fluctuations with temporal complexity among China's SATD trends. By the regression analysis of monthly STADs against simultaneous precipitation, as well as the comparative analysis of their linear trends, we found that both amount of precipitation and the change of precipitation type have important influences on SATDs. The results of convergent cross mapping analysis also revealed the causal effect of precipitation on SATDs.
\end{abstract}

\section{Introduction}

Surface sensible heat flux is an important energy source for the lower atmosphere and serves as an important component of heat balance on the ground surface. In the process of landatmosphere interaction, surface sensible heat flux plays an extremely important role in the exchange of heat between the ground surface and the atmospheric boundary layer (Ye and Gao 1979). A non-uniform horizontal distribution of surface sensible heat flux will inevitably lead to differences in atmospheric heating by the ground surface, which in turn will

Xiaohui Shi

shixh@cma.gov.cn

1 Chinese Academy of Meteorological Sciences, Beijing 100081, China cause changes in regional climate and monsoon circulation (Zhou and Huang 2010a, 2014). Surface-air temperature differences (SATDs), namely the differences between ground surface temperature (GST) and surface air temperature (SAT), are the main contributor to the surface sensible heat flux; a change in SATDs can generally reflect the change characteristics of the surface sensible heat flux (Zhou and Huang 2010b). Related studies have also revealed significant differences in the surface sensible heat flux in eastern and western China, pointing out that changes in this flux are mainly determined by SATDs (Zhou 2009; Zhou and Du 2016). Gaining an in-depth understanding of the spatiotemporal distribution and change characteristics of SATDs in China will help to better understand the spatiotemporal changes in surface sensible heat flux and reveal the intrinsic mechanisms of regional climate changes in China.

Soil temperature has some "memory" ability to record climate anomalies (Hu and Feng 2004a, 2004b), and may be 
used as a potential predictor of seasonal-scale climate anomalies and extreme events (Yang and Zhang 2016). Many studies have confirmed that as an important factor in landatmosphere interaction, GST has a major effect on climate change (Liu and Avissar 1999; Fan 2009; Wang et al. 2013). Regarding the relationship between GST and SAT, a comparative study by Beltrami et al. (2005) revealed that the two have consistent trends in changes. Qian et al. (2011) argued that the trend of increasing soil temperature in Canada coincided with an increase of SAT. However, more studies have shown that the relationship between GST and SAT can be quite complicated (Beltrami et al. 2003, 2006; Woodbury et al. 2009; Roy and Chapman 2012). It may be attributed to the fact that the land-atmosphere exchange of energy and water is affected jointly by land surface conditions (e.g., vegetation, snow, and soil humidity) and climatic changes (e.g., precipitation, solar radiation, and air humidity). Those joint effects making the GST-SAT relationship more complicated than otherwise thought (Zhang et al. 2005). Wang et al. (2016) analyzed the change characteristics of China's GST in 19612010 in comparison with SAT, finding that the change trend in GST was different from that of SAT, with the increase of GST being greater and undergoing abrupt changes later when compared with SAT.

Because of inconsistencies between changes in GST and SAT, SATDs will change accordingly. Wang et al. (2017) analyzed the spatiotemporal changes in SATDs in China between 1970 and 2015, pointing out that the annual and seasonal mean GST had similar spatial distribution and temporal evolution to the annual and seasonal mean SAT. They also observed that the winter SATDs in northern China have shown a significant increasing trend since 2005, interpreting the trend as being caused by a significant increase in GST caused by increasing snow depth. However, Liao et al. (2019) pointed out that meteorological stations in China have generally adopted automatic observation instead of manual observation since 2005. Because automatic observation of GST is based on different technical specifications when compared with manual observation, the reported winter GST in the presence of snow cover would be higher for automatic meteorological stations than for manual meteorological stations, thereby resulting in large heterogeneity in the monitoring data of winter GST. The heterogeneity in observational data is responsible for the large discrepancies in research results between studies. Given this context, it is necessary to use homogenized GST, SAT, and other data to reanalyze the change trend and its cause of SATDs in China to gain better understanding.

The remainder of this article is organized as follows. The materials and methods used in the present study are introduced in Section 2. Section 3 presents the spatiotemporal change characteristics of the monthly mean SATDs. The change characteristics of seasonal and annual mean SATDs are described in Section 4. In Section 5, the influences of precipitation on SATDs are advised and discussion and conclusions are given in section 6 .

\section{Data and methods}

\subsection{Data}

China's homogenized monthly SAT (Cao et al. 2016) and precipitation (Yang and Li 2014) data for 2419 stations and homogenized monthly GST data for 686 stations (Xu et al. 2019) were used in this study, and all data were provided by the China Meteorological Administration. Considering that there were relatively few operational meteorological stations before 1960 , the data coverage period was limited to from December 1960 to December 2016. In particular, the December data for 1960 was only used to calculate the winter mean SAT and GST. A winter mean in this study was defined as the mean over the previous December through the current February, so that the winter mean of 1961 referred to represents the mean for December 1960 and January-February 1961. Accordingly, March-May, June-August, and September-November refer to spring, summer, and autumn, respectively. When homogenizing these series of data, the data heterogeneity caused by the replacement of observation instruments was corrected, and the effects of station relocation, surrounding environmental changes, and observation time changes were taken into consideration. After station matching, SAT was subtracted from GST, leading to monthly mean SATDs at 686 stations in China.

The NCEI (National Center of Environmental Information) Pacific Decadal Oscillation (PDO) index and the Northern Hemisphere mean SAT anomaly from Climatic Research Unit at the University of East Anglia (CRUTEM4) were used to assess the influences of PDO and global warming to the interdecadal changes of SATDs in China.

\subsection{Methods}

The least-squares method was used to estimate the linear change trends of SATDs and precipitation in 1961-2016, and the linear trend was subjected to a $t$ test for statistical significance. In this study, we adopted the linear regression to explore the influence of precipitation on SATDs and the convergent cross mapping (CCM) analysis (Sugihara et al. 2012) to test the causality between precipitation and SATDs. According to the Piecewise Linear Fitting Model proposed by Tomé and Miranda (2004) for determining breakpoints of climate change trends, two criteria must be satisfied when identifying a breakpoint: (Beltrami et al. 2006) two trends over two consecutive periods should present opposite signs; and (Beltrami et al. 2005) the interval between the breakpoints 
must equal or exceed a given value, which was set to 11 years in this study. The timescales of interdecadal change generally range from decade to multi-decade, so we selected 11 years as a lower limiting value. Based on these criteria, the interdecadal trend breakpoints of China's SATDs in 19612016 were determined.

The basic working principle of the Piecewise Linear Fitting Model is as follows: (Beltrami et al. 2006) according to the time scale of the climate data series in question, the minimum interval between trend breakpoints is set; and (Beltrami et al. 2005) the identification criterion of trend breakpoints is specified (depending on the research purpose, the opposite signs between the two linear trends over two consecutive periods was used as the criterion in this study). Under the premise that the time interval between two adjacent trend breakpoints must be greater than or equal to a given minimum value (that is, the climatic fluctuations with a change period shorter than this minimum interval are filtered out), a variety of combinations of consecutive periods was considered by calculating the linear trends over each period, evaluating whether trend breakpoints existed according to the above criteria. At the end, the optimal combination among all period combinations with trend breakpoints was statistically determined, i.e., the solution that minimizes the residual sum of squares was chosen. That is, the linear trends and trend breakpoints at an optimal time interval between a given time window (e.g., 1961-2016) can be identified.

\section{Trends of monthly SATDs}

First, the homogenized monthly GST, SAT, and SATDs at 686 stations of each year were summed individually and divided by 686 to obtain the station-averaged monthly series of GST, SAT, and SATDs in China during 1961-2016, followed by the calculation of linear trends over the 56 years (Fig. 1). Only March, April, and May exhibited increasing trends in homogenized SATDs, while the other months exhibited decreasing trends. The months with decreasing trends passed significance test $(p<0.05)$ except for January, October, and November. In particular, the increasing trend of April was most significant $(p<0.05)$, reaching $0.0076{ }^{\circ} \mathrm{C} / \mathrm{a}$, while the increasing trends of March and May were weak and statistically insignificant. August exhibited the most significant decreasing trend of $-0.0058^{\circ} \mathrm{C} / \mathrm{a}$. July also showed a significant decreasing trend in homogenized SATDs, which was inconsistent with the previous finding by Liao et al. (2019) where July SATDs showed an increasing trend; this difference likely occurred because different data was used in that study.

Trend comparison between monthly homogenized GST and SAT (Fig. 1b) revealed that GST exhibited greater increasing trends in March-May than SAT, while the opposite was observed in other months. That is, SAT exhibited greater increasing trends than GST, especially in July and August when GST even exhibited decreasing trends. This coincided with the trends of monthly SATDs where the months with greater increasing trends in GST also exhibited larger SATDs, and the months with greater increasing trends in SAT exhibited smaller SATDs. Meanwhile, the increasing trends in SAT and GST were most obvious from November to the next April, which was in agreement with the previous finding that the increasing trends in SAT and GST are greater in winter and spring than in other seasons (Cao et al. 2016; Xu et al. 2019).

To understand the spatial distribution of the long-term trends of monthly homogenized SATDs in China, the linear trends of monthly SATDs were calculated over 1961-2016 for each monitoring station, which were subjected to $t$ tests for statistical significance. In April (Fig. 2a), most of the monitoring stations presented increasing trends of SATDs and the monitoring stations showing significant increasing trends $(p<0.05)$ were mainly concentrated in four regions, namely northeastern China, northern China, northwestern China, and the Chinese part of the Qinghai-Tibet Plateau. However, the distribution was somewhat different in August, with the monitoring stations with decreasing trends were mainly distributed in the southeastern region east of $105^{\circ} \mathrm{E}$ and south of $35^{\circ} \mathrm{N}$ while the other monitoring stations in general still exhibited increasing trends (Fig. 2b). The above spatial distribution pattern showing monitoring stations with increasing trends in monthly SATDs that were mainly concentrated in the four regions listed above was also observed in other months (figures omitted), indicating that the northern regions of China had more significant increasing trends in SATDs than the southern regions over the past 50 years.

Table 1 presents the trend breakpoints of station-averaged monthly SATDs in China in 1961-2016. April was unique, because it exhibited significant linear increasing trends without any interdecadal trend breakpoints over the 55 years (Fig. 3a). The SATDs of November and December exhibited interdecadal trend breakpoints at 2002 and 1999, respectively, showing a change from a decreasing trend to an increasing trend. The other months each exhibited two interdecadal trend breakpoints, with the months of January, February, March, August, and October showing changes from an increasing trend to a decreasing trend and then back to an increasing trend; and the months of May, June, July, and September showed the opposite change. Taking the interdecadal trend breakpoints of the station-averaged August SATDs in China as an example (Fig. 3b), the SATDs increased linearly during 1961-1990 but linearly decreased during 1990-2004 and then increased again in 2004-2016. This observation shows that in the case of a significant, long-term linear decreasing trend in SATDs (Fig. 1a), obvious interdecadal fluctuations still existed, indicating the complexity of the changes in SATDs. Moreover, Table 1 shows that the breakpoint years for each 
Fig. 1 Linear trends $\left({ }^{\circ} \mathrm{C} / \mathrm{a}\right)$ of China's homogenized stationaveraged monthly mean a surface-air temperature differences (SATDs) and $\mathbf{b}$ ground surface temperature (GST) and surface air temperature (SAT) during 1961-2016. The dotted bars indicate that the trends are statistically significant $(p<0.05)$
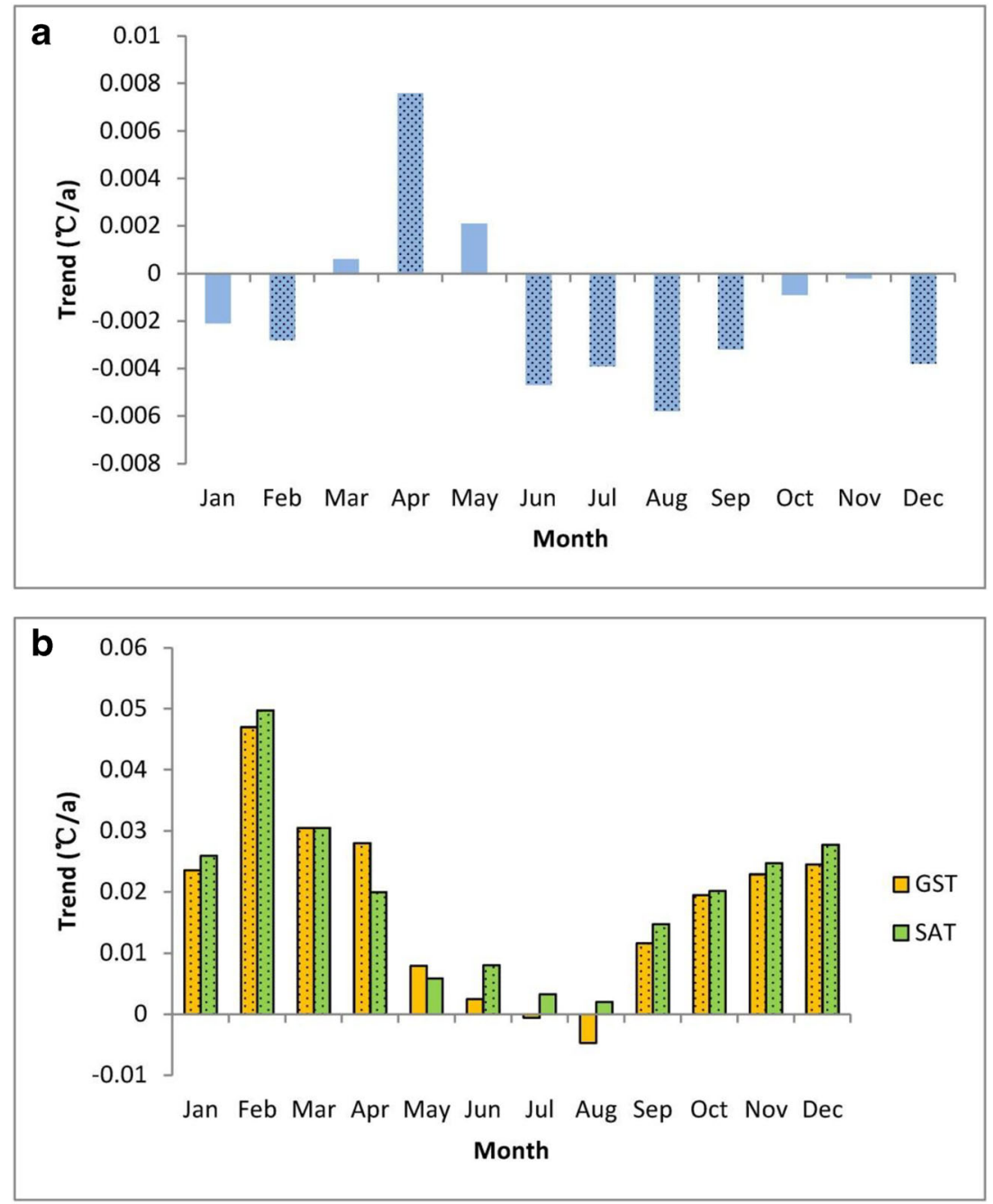

monthly series of SATDs did not present a simple sequential pattern. In general, the most recent breakpoint years after which monthly SATDs showed increasing trends (JanuaryMarch, August, and October-December) were later than the most recent breakpoint years after which monthly SATDs showed decreasing trends (May-July and September).

\section{Change trends of seasonal and annual mean SATDs}

Figure 4 presents the station-averaged, seasonal, and annual mean SATDs in China in 1961-2016 as well as the linear trends. Winter, spring, summer, and autumn are defined as the periods from the previous December to the current February (DJF), from March to May (MAM), from June to August (JJA), and from September to November (SON), respectively, with an annual mean referring to the mean over the 12 months. Except for spring when SATDs showed a significant increasing trend of $0.0034{ }^{\circ} \mathrm{C} / \mathrm{a}(p<0.05)$, the other seasonal mean SATDs and annual mean SATDs all showed significant decreasing trends $(p<0.05)$, with summer mean SATDs showing the largest decreasing trend of $-0.0048^{\circ} \mathrm{C} /$ a (Fig. 4). We also used the Mann-Kendall test to verify the significance of the change trends for seasonal and annual mean SATDs. The $Z$ value is $-3.66,3.12,-3.26,-2.52$, and -2.24 for winter, spring, summer, autumn, and annual mean SATDs, respectively. The absolute values of them exceed the confidence level at $\alpha=0.05\left(Z_{0.05}=1.96\right)$. It further demonstrate the significant increasing trend in spring, but decreasing trends in the other three seasons and annual mean SATDs in China. This observation is consistent with the trend of monthly SATDs presented in the previous section, but it is different from the observation made by Wang et al. (2017) that in 1970-2015, the seasonal mean SATDs and annual mean SATDs in China showed increasing trends, with winter mean SATDs showing the largest increasing trend. The inconsistency may be attributed to the fact that the raw data in the study of Wang et al. (2017) were not homogenized. 


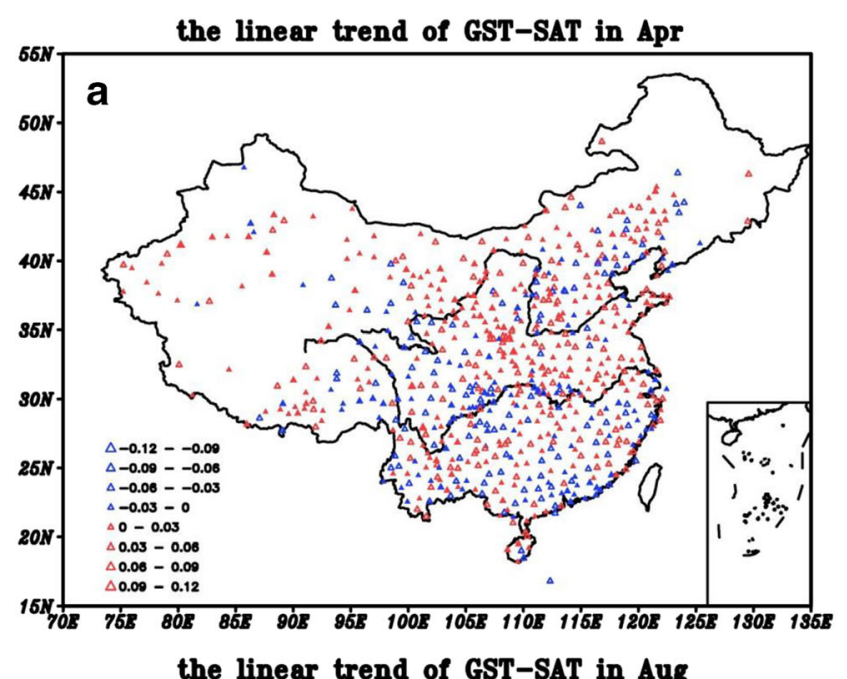

Since 2005, meteorological stations in China have generally adopted automatic observation instead of manual observation. During the manual observation period, the thermometers were required to be removed from the snow cover and placed on the snow surface when the surface was covered by snow, so GST represents the snow surface temperature. However, GST is observed by one platinum metallic thermometer in automatic observation. The platinum metallic thermometers were not required to be moved when there is snow cover on the land surface, and GST measured by an automatic weather station is the temperature of the soil surface under the snow cover. This transformation in the method of measurement may lead to a warming effect on the observed record of GST and the abrupt increasing of GST after 2005 in the work by Wang et al. (2017). Unfortunately, snow surface temperature observations were not collected before 2007 in China and cannot be used to replace GST observations at some meteorological stations in Northeast and Northwest China which frequently covered by snow. For eliminating the impact from the vast inhomogeneity of GST between manual observation and automatic observation, the data at these stations were not processed in the homogenization of GST, i.e., the homogenized data used in this study firstly excluded these meteorological stations in Northeast and Northwest China. After that, the homogenized method and metadata were further utilized in data at the other stations to diminish inhomogeneities caused by other nonnatural factors (e.g., relocation of station, environmental change around the station, and change in observational time).

The spatial distribution of the linear change trend for seasonal mean SATDs of each station in 1961-2016 is presented in Fig. 5. The spring mean SATDs presented linear increasing trends at most stations (Fig. 5b), and this observation was similar to that for April (Fig. 2a). In contrast, the trends for summer mean SATDs (Fig. 5c) were similar to those for

Table 1 Interdecadal breakpoint years in the trends of China's homogenized, station-averaged monthly mean surface-air temperature differences in 19612016

\begin{tabular}{llll}
\hline Month & Number of breakpoints & Breakpoint year & Changes in trend signs \\
\hline Jan & 2 & 1980,1999 & +-+ \\
Feb & 2 & 1971,2002 & +-+ \\
Mar & 2 & 1986,1997 & +-+ \\
Apr & 0 & & + \\
May & 2 & 1971,1982 & -+- \\
Jun & 2 & 1971,1982 & -+- \\
Jul & 2 & 1974,1985 & -+- \\
Aug & 2 & 1990,2004 & +-+ \\
Sep & 2 & 1972,1998 & -+- \\
Oct & 2 & 1987,2000 & +-+ \\
Nov & 1 & 2002 & -+ \\
Dec & 1 & 1999 & -+ \\
\hline
\end{tabular}


Fig. 3 China's homogenized, station-averaged monthly mean surface-air temperature differences (SATDs; ${ }^{\circ} \mathrm{C}$ ) during $1961-$ 2016 and segmented trends separated by identified interdecadal breakpoint years for $\mathbf{a}$ April and $\mathbf{b}$ August. Triangles, dotted lines, and solid lines indicate the years when the trends change, segmented linear trends, and the SATDs, respectively
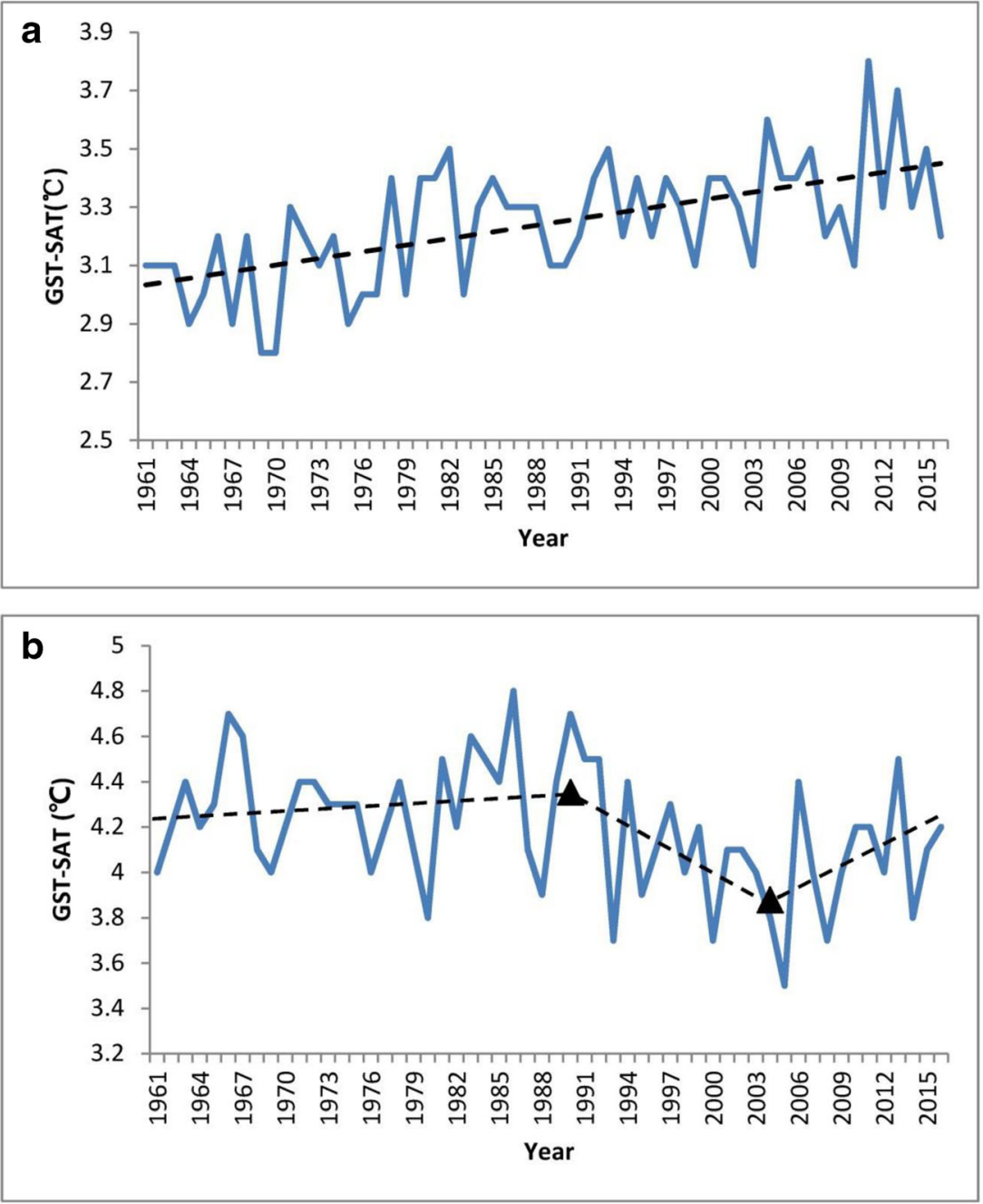

August (Fig. 2b); that is, most of the stations in southeastern China presented linear decreasing trends in summer mean SATDs. The trends of winter (Fig. 5a) and autumn (Fig. 5d) mean SATDs showed spatial distribution patterns between those for spring and summer; that is, fewer stations had linear increasing trends for winter and autumn than for spring and fewer stations had linear decreasing trends for winter and autumn than for summer. In general, the stations that presented linear increasing trends in SATDs during 1961-2016 were mainly distributed in northeastern China, northern China, northwestern China, and the Chinese part of the QinghaiTibet Plateau, while the stations that presented linear decreasing trends were mainly distributed in southeastern China. Such spatial patterns were evident for each season, and they even existed in the spatial distribution of annual mean SATDs (Fig. 6), further confirming that SATDs in the northern regions of China during 1961-2016 presented relatively obvious increasing trends.

Winter SATDs experienced an interdecadal breakpoint during 1961-2016, changing from a decreasing trend to an increasing trend after 2000 (Fig. 7a), which was earlier than the breakpoint year of 2005 identified by Wang et al. (2017) who argued that the sudden increase in winter SATDs was caused by increased snow cover. However, more researches need to be conducted to verify the possible relationship between the increasing trend of SATDs and the changes in snow cover. The trend of spring SATDs experienced two breakpoints, that is, the trend increased during 1961-1982, decreased between 1982 and 1998, and then increased again after 1998 (Fig. 7b). Summer presented a similar pattern of SATD trend change to spring, but the breakpoint years were relatively later, namely 1990 and 2003 (Fig. 7c). Autumn, however, presented a different pattern; that is, the trend of autumn SATDs experienced two interdecadal breakpoint years much earlier in 1972 and 1983 compared with spring and summer, with the trend changed in the order of decreasing, increasing, and decreasing (Fig. 7d). Annual mean SATDs presented trend breakpoint years of 1986 and 1999, a pattern similar to 
Fig. 4 China's homogenized station-averaged seasonal and annual mean surface-air temperature differences (SATDs; ${ }^{\circ} \mathrm{C}$ ) during 1961-2016 (solid lines) and the linear trends (dotted lines)

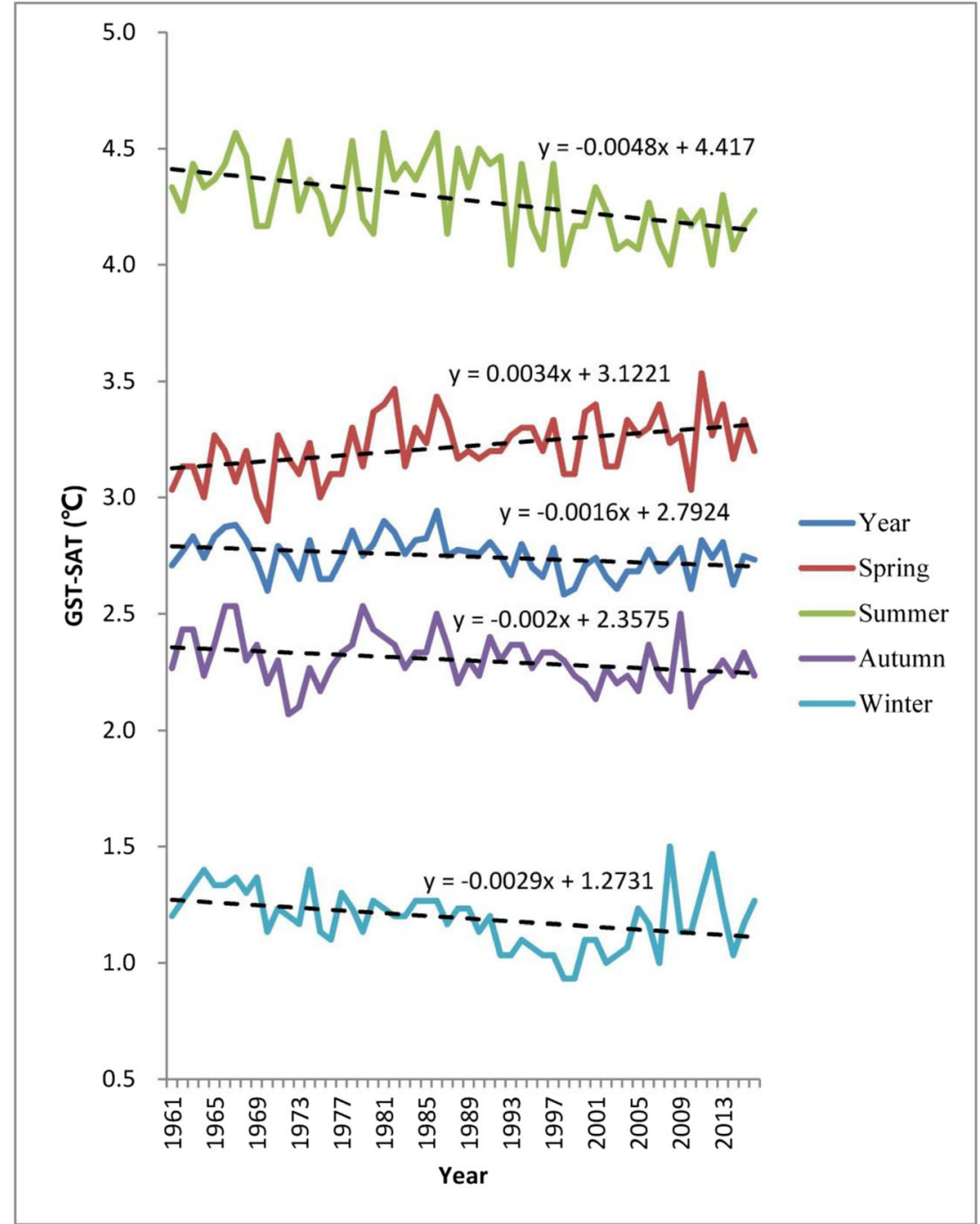

that for spring mean SATDs; that is, the trend increased in 1961-1986, decreased during 1986-1999, and increased again during 1999-2016 (Fig. 8).

\section{Influence of precipitation on SATDs}

In order to understand the possible causes of the variation in SATDs, we calculated the monthly simultaneous linear regression of the homogenized SATDs against the homogenized precipitation in each meteorological station from 1961 to 2016 (Fig. 9). It showed that the spatial distribution of monthly regression coefficient of SATDs against precipitation could be divided into two types: warm season mode (April to September, Fig. 9b-Fig. 9g) and cold season mode (November to February of the following year, Fig. 9i-Fig. 91). March (Fig. 9a) and October (Fig. 9h) could be regarded as the transition period between these two correlation types.
For the warm season mode (Fig.9b-Fig.9g), due to the higher air temperature, the main form of precipitation was rainfall. The increase of rainfall leads to the higher soil moisture content. The more heat energy will be absorbed from the soil in the evaporation process, which lowered the GST and eventually reduced SATDs. Therefore, during the period from April to September, the regression coefficients of SATDs against precipitation were negative at most stations in China. By comparing Figs. 10 and 2, it could be found that the linear trends of precipitation and SATDs were opposite in most meteorological stations from 1961 to 2016. In April, the precipitation of most stations in central and eastern China showed a significant decreasing trend (Fig. 10a), while SATDs of many stations in this region showed an increasing trend (Fig. 2a). At the same time, SATDs tended to decrease correspondingly at the stations with increasing precipitation in other regions. The situation in August was similar to that in April. Especially in eastern China, the trend of "south flood and north drought" in precipitation (Fig. 10b) was corresponding to the change trend 

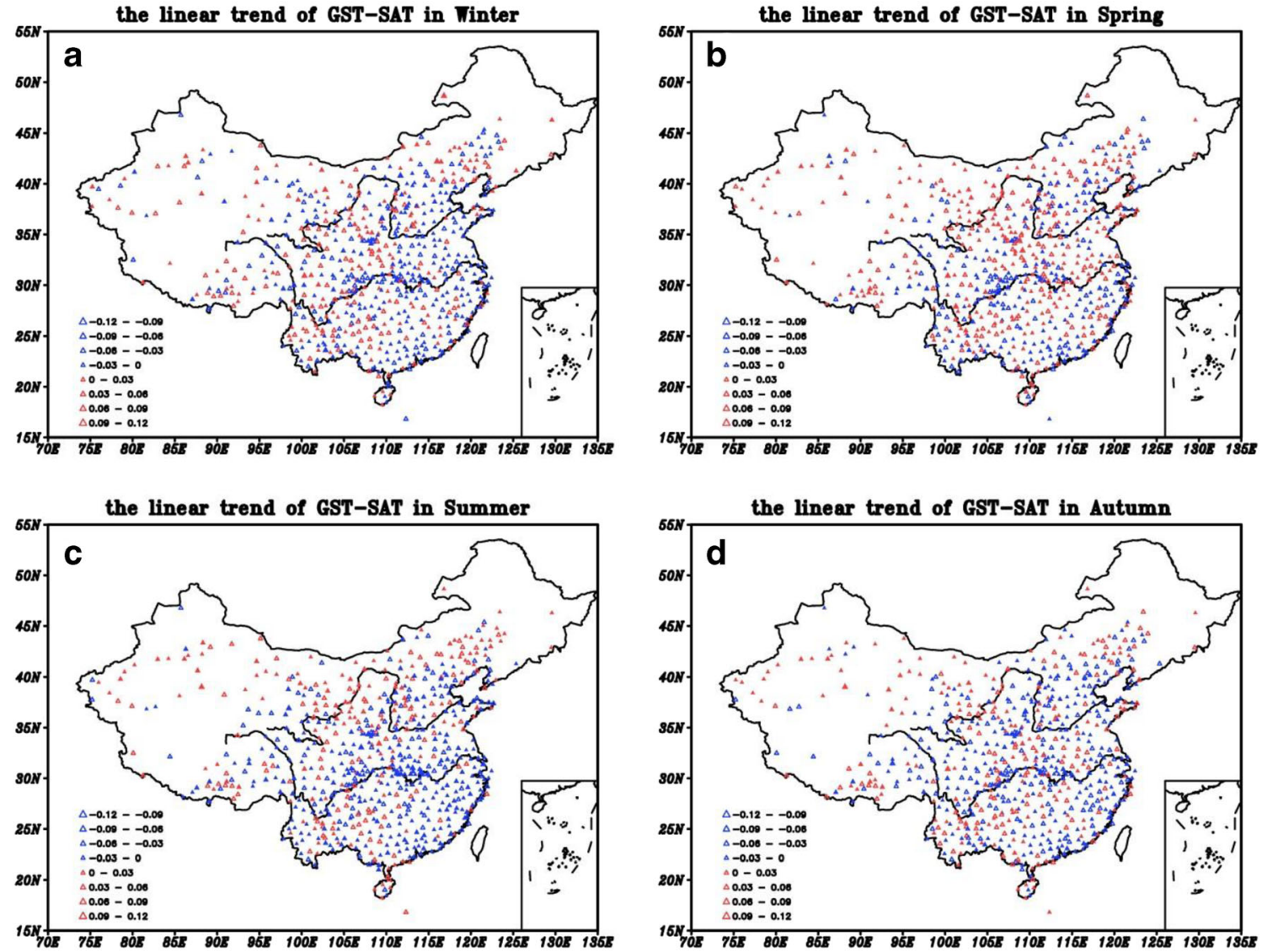

Fig. 5 Spatial distribution of the linear trends $\left({ }^{\circ} \mathrm{C} / \mathrm{a}\right)$ of China's homogenized seasonal mean surface-air temperature differences (SATDs) at the meteorological stations in 1961-2016: a winter; b spring;

c summer; $\mathbf{d}$ autumn. The red and blue triangles indicate increasing and decreasing trends, respectively, and the solid color triangles indicate stations with statistically significant linear trends $(p<0.05)$

Fig. 6 Spatial distribution of the linear trends $\left({ }^{\circ} \mathrm{C} / \mathrm{a}\right)$ of China's homogenized annual mean surface-air temperature differences (SATDs) at various meteorological stations in 1961-2016. The red and blue triangles indicate increasing and decreasing trends, respectively, and the solid color triangles indicate stations with statistically significant linear trends $(p<0.05)$

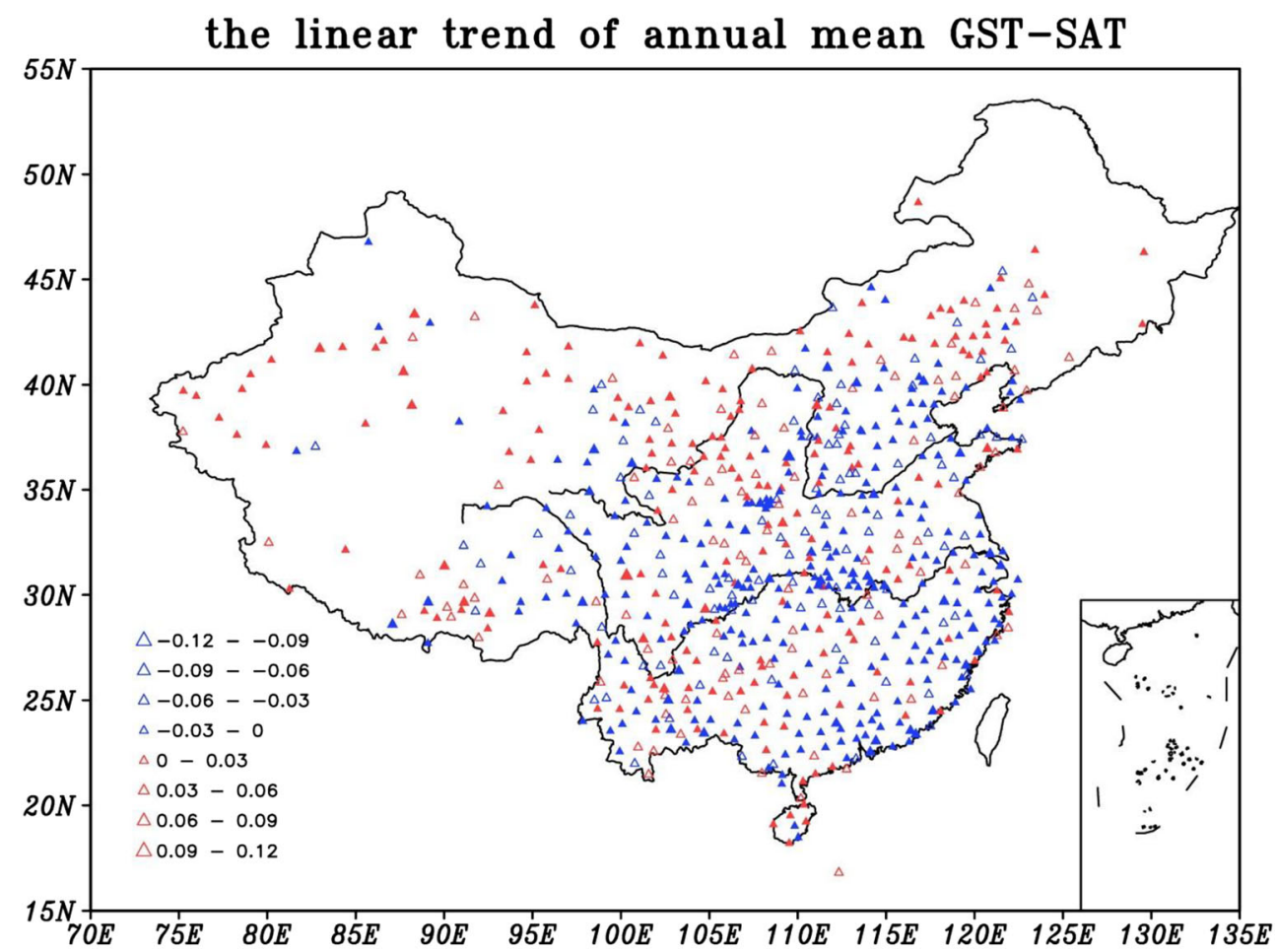



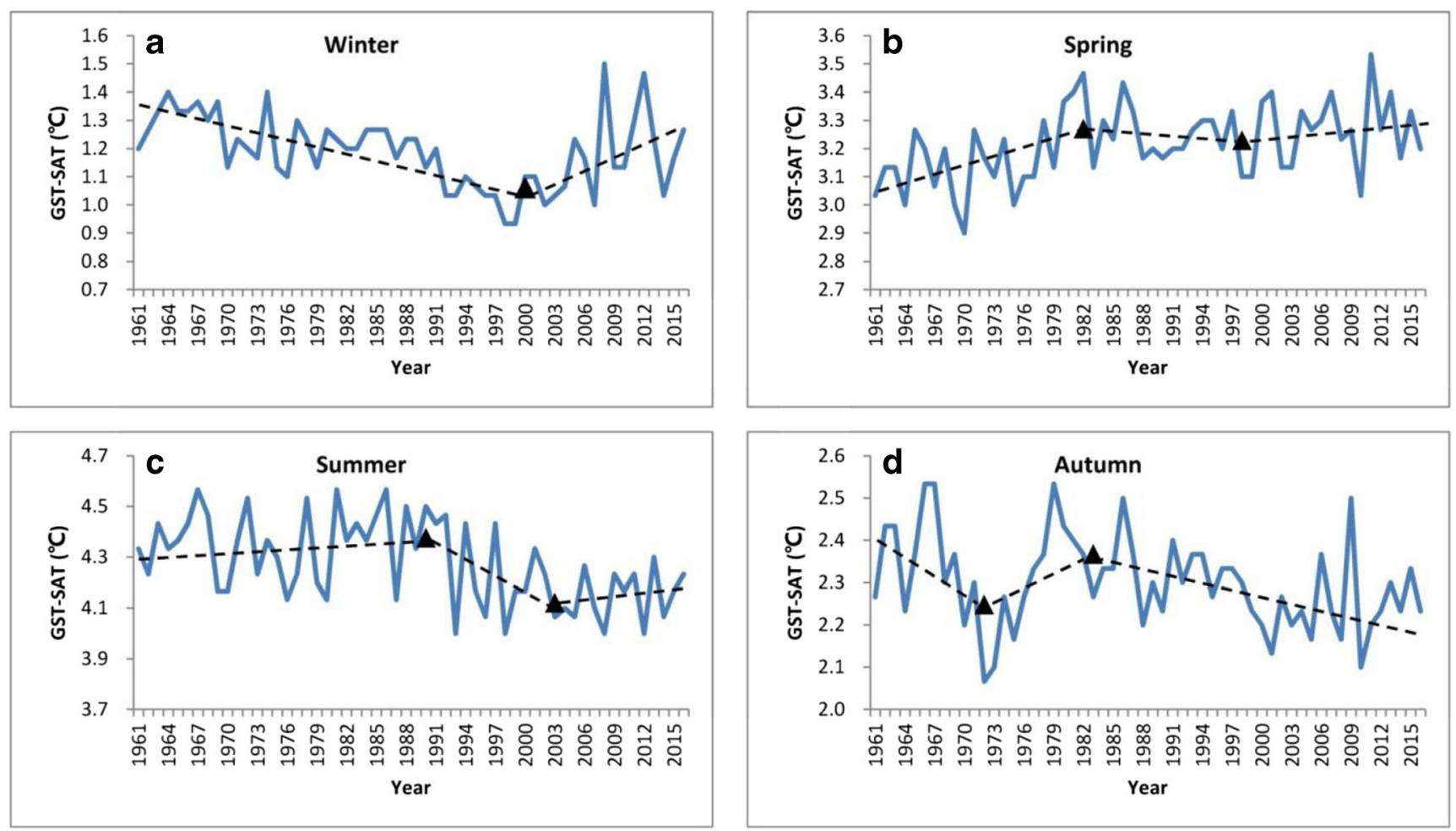

Fig. 7 China's homogenized, station-averaged seasonal mean surface-air temperature differences (SATDs; ${ }^{\circ} \mathrm{C}$ ) during 1961-2016 and segmented trends separated by identified interdecadal breakpoint years for winter (a), spring (b), summer (c), and autumn (d). The triangles, dotted lines, and

of "south decrease and north increase" in SATDs (Fig. 2b). In October (Fig. 9h), more stations showed positive regression coefficients of SATDs against precipitation and the regression type gradually shifted to cold season mode.

From Fig. 9i-Fig. 91, we can see that the main characteristic of the cold season mode is "north positive and south negative." It might be due to the lower air temperature in northern China during the period from November to February of the following year. Snowfall was the main type of precipitation.

solid lines indicate the years when the trends change, segmented linear trends, and SATDs, respectfully. Note: GST and SAT represent homogenized ground and air surface temperatures, respectively

The increase in snow cover blocked the heat loss of the soil and increased GST. On the other hand, more heat energy was absorbed from the air during the melting process of snow, which reduced the SAT. The joint effect would cause the increase of SATDs. Therefore, there was a positive regression coefficient of SATDs against precipitation in northern China. In southern China, because of the higher temperature, the precipitation was still dominated by rainfall. The relationship between precipitation and SATDs still maintained a negative

Fig. 8 China's homogenized, station-averaged annual mean surface-air temperature differences (SATDs; ${ }^{\circ} \mathrm{C}$ ) during $1961-$ 2016 and segmented trends separated by identified interdecadal breakpoint years. The triangles, dotted line, and solid line indicate the years when the trends change, segmented linear trends, and SATDs, respectively

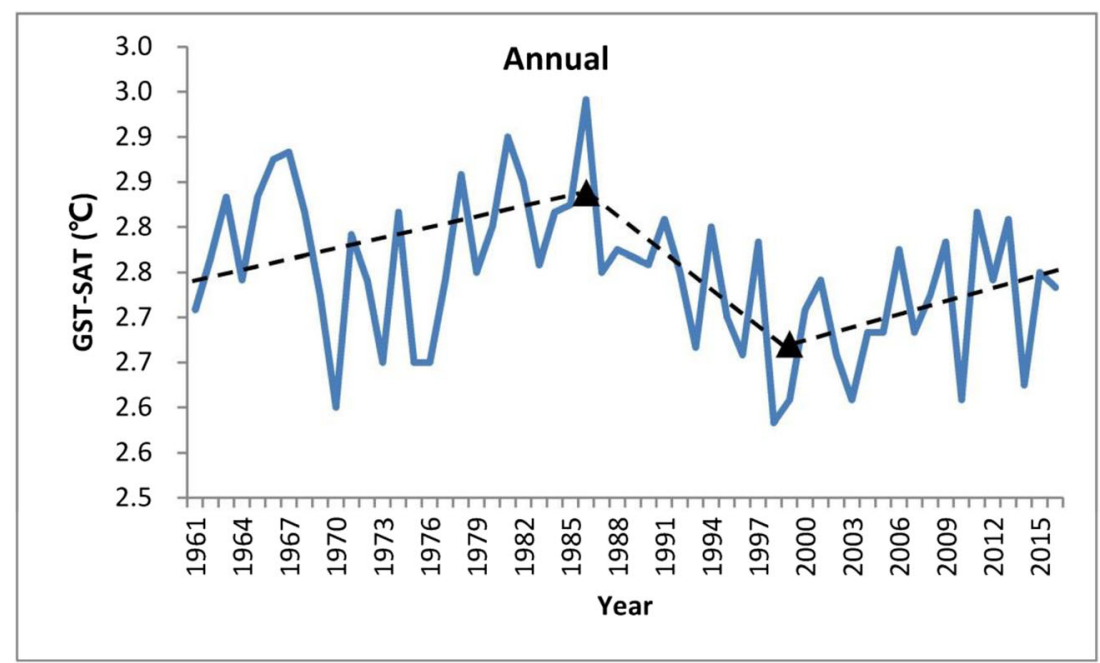



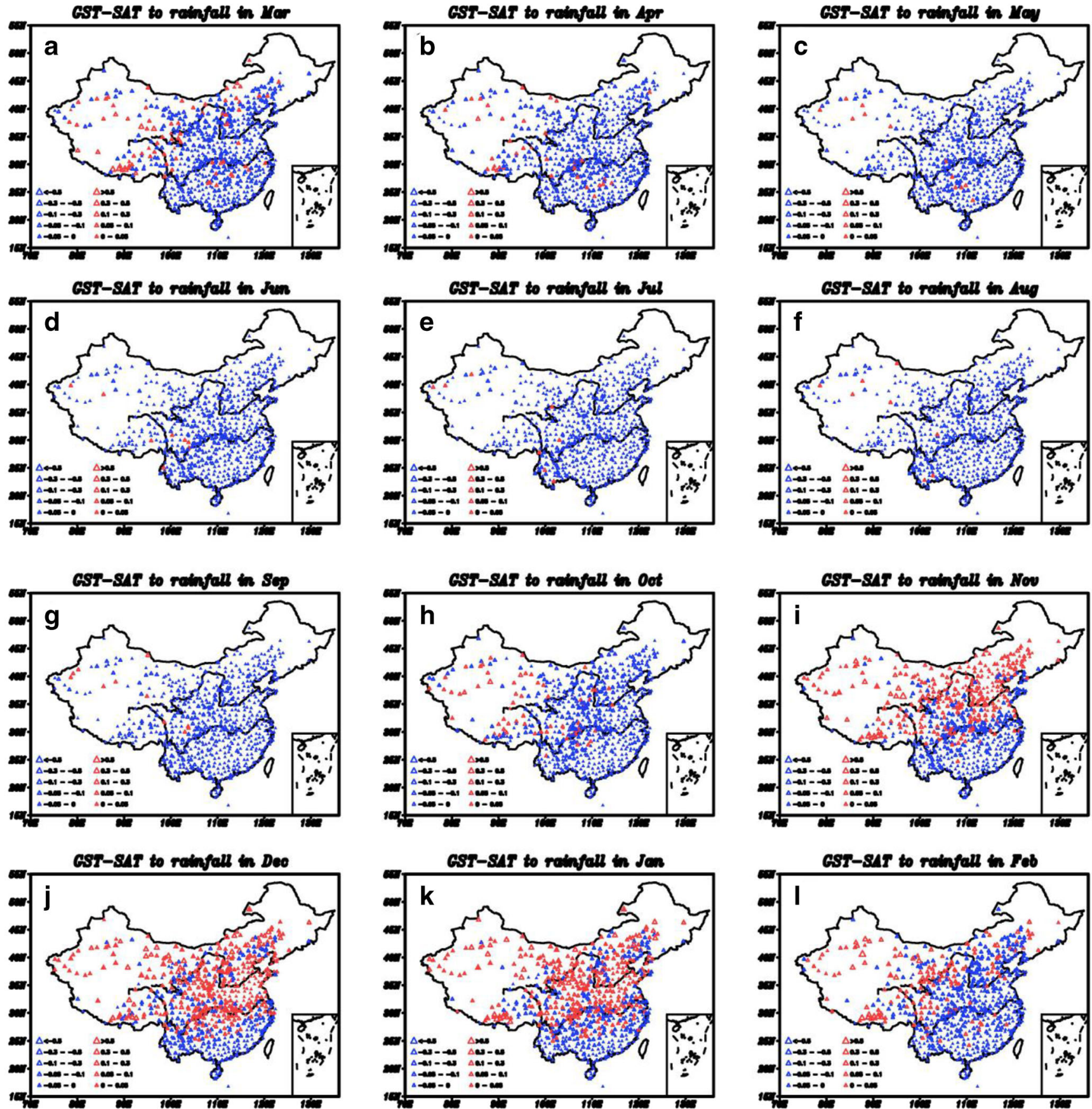

Fig. 9 Simultaneous regressions of homogenized monthly mean SATDs against precipitation at the meteorological stations in China during 19612016 for a March; b April; c May; d June; e July; f August; g September; h October; i November; j December; $\mathbf{k}$ January; I February. Red and blue

triangles indicate positive and negative regression coefficients, respectively; solid color triangles indicate stations with statistical significance $(p<0.05)$

correlation and there was a negative regression coefficient of SATDs against precipitation in this region. Taking December as an example (Fig. 11), it showed that the changing trend of precipitation was opposite to that of SATDs at most stations in southern China during the period 1961-2016, while the precipitation and SATDs showed the same trends at most stations in northern China. In March (Fig. 9a), the positive regression coefficient of STADs against precipitation at some stations in northern China turned to negative and the regression type began to transform into warm season mode.

The results of above monthly simultaneous regression analysis of SATDs against precipitation, as well as the comparative analysis for their linear trends, showed that both the amount of precipitation and the change of precipitation type had important influences on SATDs. In general, more rainfall would reduce the GST, and then lead to the decrease of 
Fig. 10 Spatial distribution of the linear trends $(\mathrm{mm} / \mathrm{a})$ of China's homogenized monthly mean precipitation at the meteorological stations in 1961-2016 for a April and $\mathbf{b}$ August. Red and blue triangles indicate increasing and decreasing trends, respectively; solid color triangles indicate stations with statistically significant linear trends $(p<0.05)$
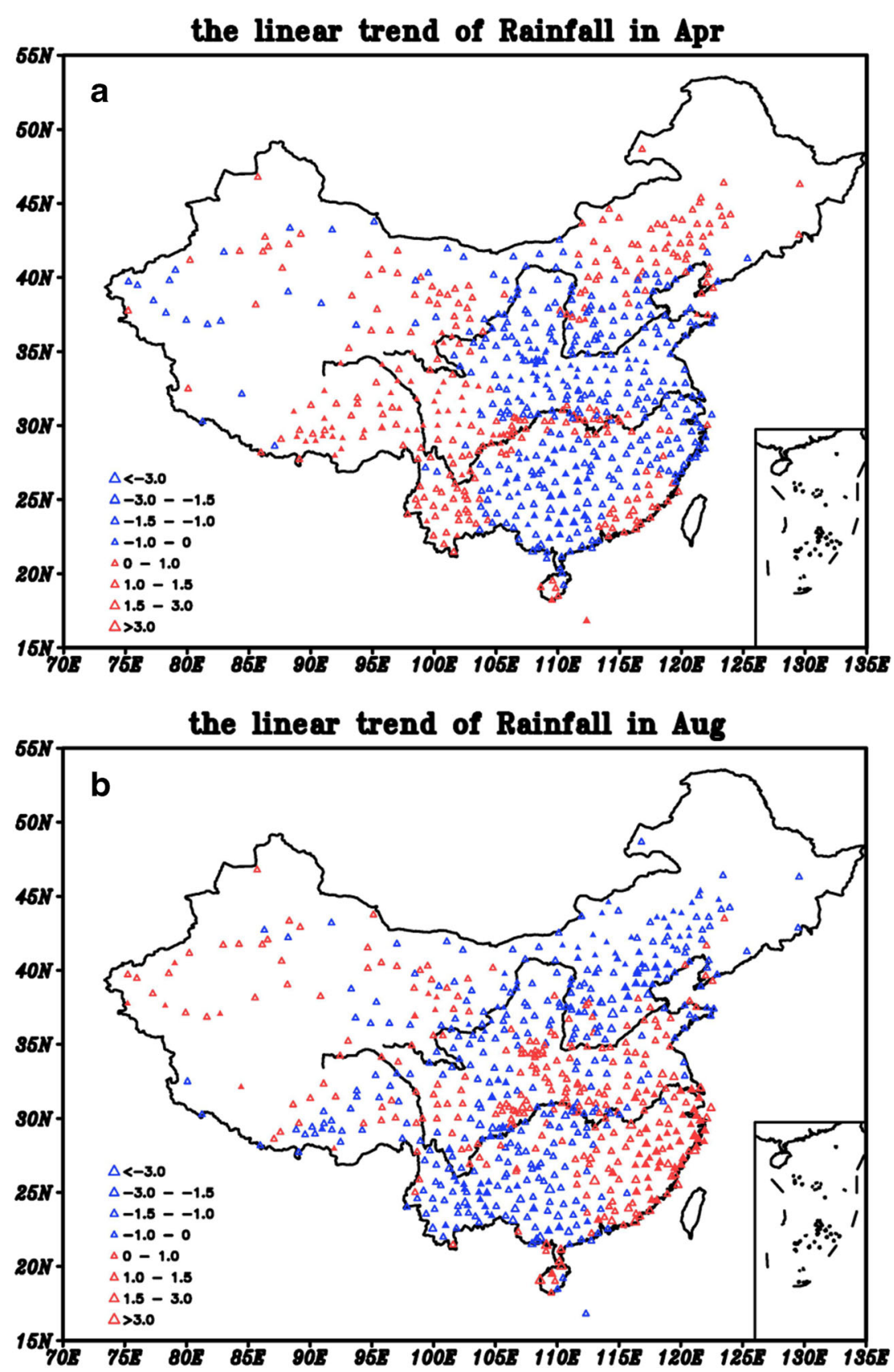

SATDs. while more snowfall would cause the increase of GST and decrease of SAT, finally the increase of SATDs, and vice versa.

To verify the causal effect of precipitation on SATDs, a CCM analysis for the monthly station-averaged SATDs and precipitation in China in 1961-2016 was conducted (Fig. 12). The figure indicated bidirectional forcing between SATDs and precipitation, and the influence of precipitation on SATDs was somewhat stronger than that of SATDs on precipitation. Overall, these results demonstrated that precipitation could indeed cause the change of SATDs, but the impact of SATDs on precipitation also cannot to be neglected. The more in-depth studies need to be carried out for understanding the interactions of them.

\section{Conclusion and discussion}

Based on Chinese latest homogenized series of GST and SAT, the present study performed detailed analysis of the long-term trends of SATDs in 1961-2016, investigated temporal and spatial changes in the trends of monthly, seasonal, and annual mean SATDs. The results showed that only March, April, and May presented increasing trends of station-averaged monthly 
Fig. 11 Spatial distribution of the linear trends of China's homogenized monthly mean SATDs $\left(\mathbf{a},{ }^{\circ} \mathrm{C} / \mathrm{a}\right)$ and precipitation (b, $\mathrm{mm} / \mathrm{a}$ ) at the meteorological stations in 1961-2016 for December. Red and blue triangles indicate increasing and decreasing trends, respectively; solid color triangles indicate stations with statistically significant linear trends $(p<0.05)$

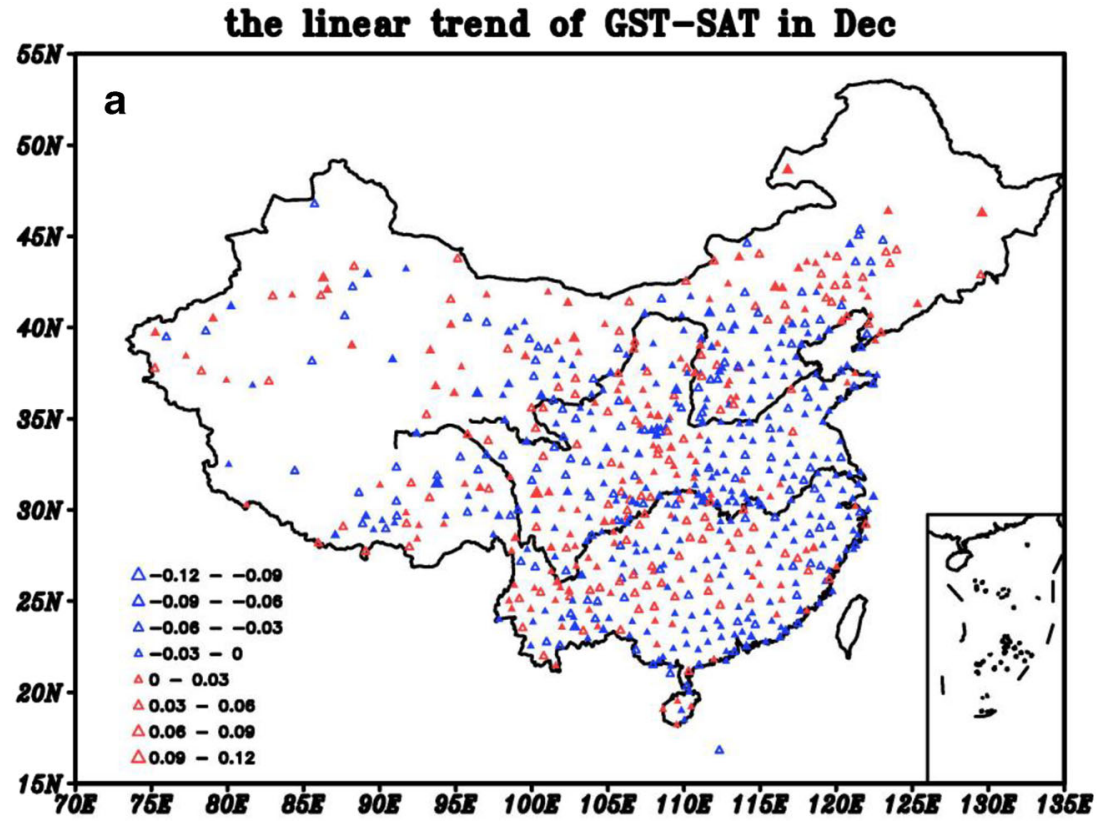

the linear trend of Rainfall in Dec

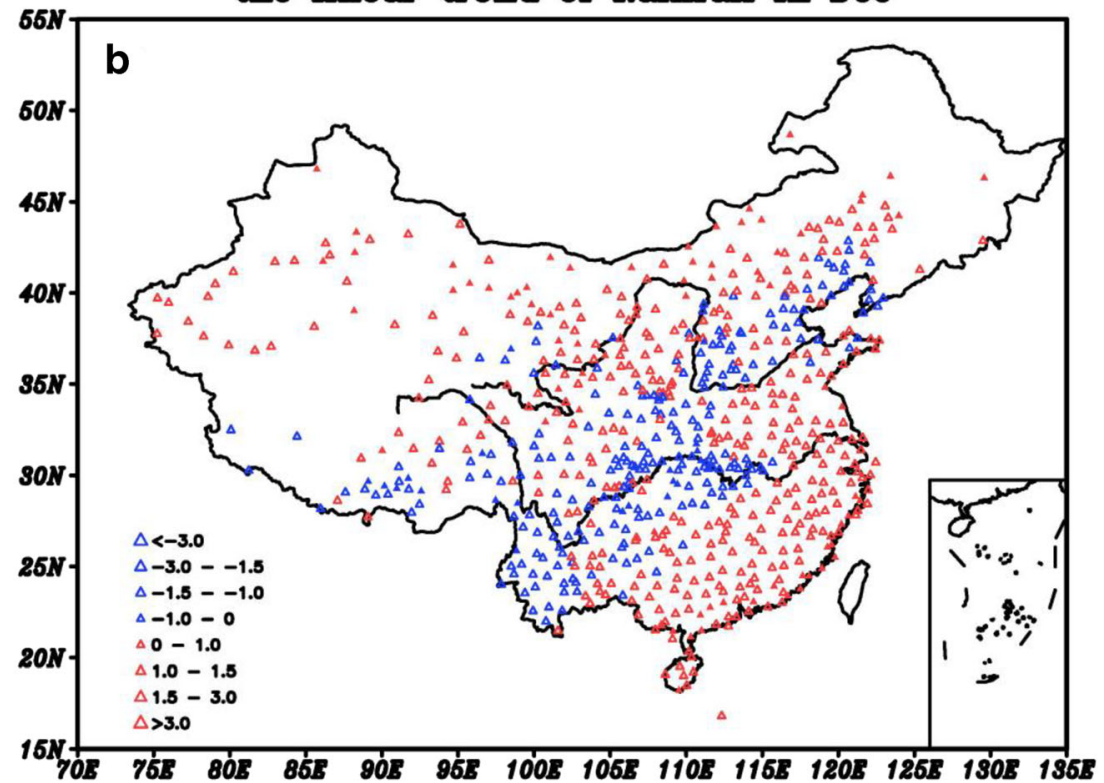

SATDs in China while the other months presented decreasing trends, with the most substantial increasing trend occurring for April and the most substantial decreasing trend occurring for August. The analysis results of the long-term linear trends of station-averaged, seasonal, and annual mean SATDs in China revealed that the annual SATDs and the summer, autumn, and winter SATDs presented significant linear decreasing trends in 1961-2016, while the spring SATDs presented a significant linear increasing trend. They are different from the results of previous studies (Wang et al. 2017; Liao et al. 2019). The discrepancy may have been caused by the fact that the raw data in the studies of them were not homogenized.
When it comes to spatial distribution, the stations with increasing trends in monthly, seasonal, and annual SATDs were mainly distributed in northeastern China, northern China, northwestern China, and the Chinese part of the Qinghai-Tibet Plateau. This distribution pattern indicated that increasing trends of SATDs in the northern regions of China were more obvious than the southern regions during 1961-2016.

The test results of interdecadal trend breakpoints indicated that the trends of SATDs in China presented obvious interdecadal fluctuations with temporal complexity. Moreover, the trend breakpoint years did not present a simple sequential pattern, but in general the most recent breakpoint 
Fig. 12 Cross map skill as a function of the length of library for SATDs causing precipitation (blue curve) and precipitation causing SATD (red curve).

(Generated by free software R, https://www.R-project.org/)

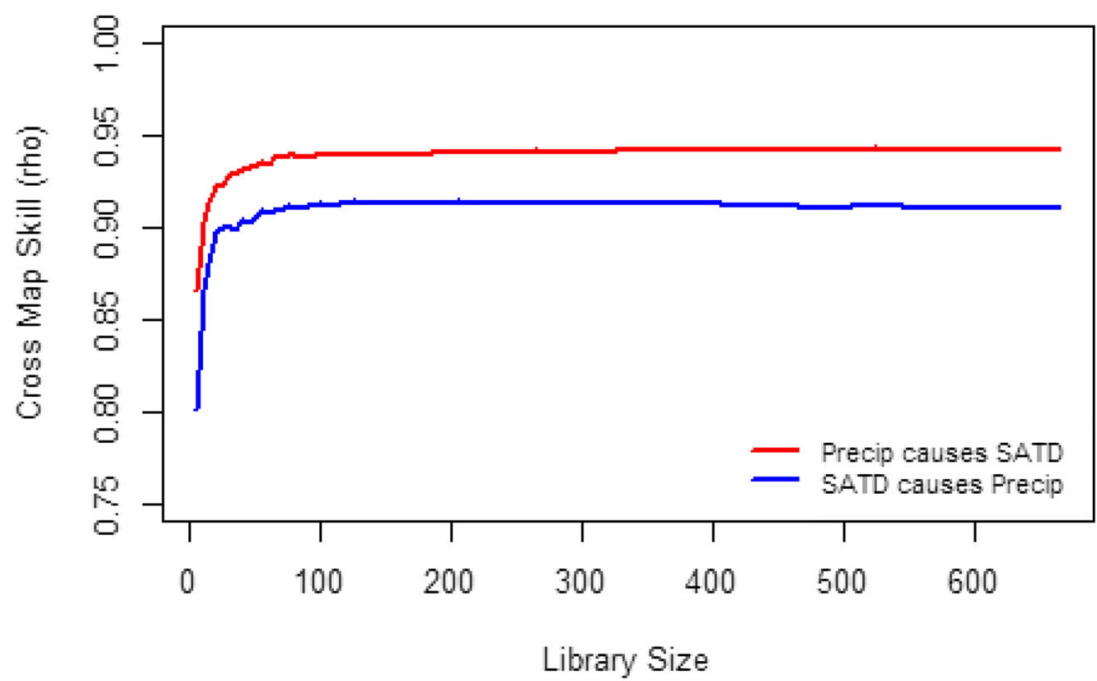

years after which SATDs showed increasing trends were later than the most recent breakpoint years after which SATDs showed decreasing trends. However, this phenomenon is not well understood, with a need to conduct more in-depth research.

By simultaneous regressions of homogenized monthly mean SATDs against precipitation at each station and comparing their linear trends, we found that both the amount of precipitation and the variation of precipitation type could affect the change trend of SATDs. That is, more rainfall made lower GST, and then SATDs decreased, while more snowfall led to increased GST and decreased SAT, finally the increased SATDs, and vice versa. The results of CCM analysis further demonstrated the causal effect of precipitation on SATDs.

SAT is a component of SATDs, so the global warming should affect the SATDs. Previous research have found the global warming hiatus during 1951-1976 and 1998-2012 (Kosaka and Xie 2013; Maruyama 2019). It denotes the fluctuations in global cooling or warming at a decadal scale. Does the global warming hiatus relate to the increasing trend of the SATDs? In addition, the Pacific Decadal Oscillation (PDO) is often described as a long-lived El Niño-like pattern of Pacific climate variability (Zhang and Levitus 1997) and a dominant decadal oscillation that has important influences on the climate in China (Zhu et al. 2015). Could PDO be as a potential factor that affects the interdecadal changes of the SATDs trends? We made a simple analysis by the multiple linear regressions of SATDs against NCEI PDO index and CRUTEM4 and found that the interdecadal increasing trend of STADs would generally be benefit from PDO but blocked by global warming. Nevertheless, the global warming and PDO cannot fully explain the interdecadal changes in SATDs, especially in the global warming hiatus periods. In addition, studies have confirmed that significant interdecadal changes exist in the East Asian winter, summer monsoons, and summer precipitation in China (Ding et al. 2009, 2014; Zhu et al. 2015). A question arises: Will the interdecadal trend breakpoints of China's SATDs also be related to the above interdecadal changes? We plan more detailed study on the physical mechanisms leading to the interdecadal changes of SATDs in China for further understanding.

Acknowledgments We thank the National Meteorological Information Center of the China Meteorological Administration for providing the homogenized monthly surface air temperature, ground surface temperature, and precipitation data from mainland China used in this study. The NCEI PDO index was accessed from NOAA, USA (https://www.ncdc. noaa.gov/teleconnections/pdo/). The CRU averaged temperature in Northern hemisphere was obtained from the Met Office Hadley Centre observations datasets, UK (https://www.metoffice.gov.uk/hadobs/ crutem4/data/diagnostics/hemispheric/northern/index.html). We would also like to thank the anonymous reviewers whose critical reviews and valuable suggestions were important to the improvement of the manuscript.

Authors' contribution All authors contributed to the study conception and design. Material preparation, data collection, and analysis were performed by Xiaohui Shi and Jinqiu Chen. The first draft of the manuscript was written by Xiaohui Shi and all authors commented on previous versions of the manuscript. All authors read and approved the final manuscript.

Funding The National Natural Science Foundation of China (No. 41775060) and the Basic Scientific Research and Operation Foundation of Chinese Academy of Meteorological Sciences (No. 2018Z006) jointly funded this study.

\section{Compliance with ethical standards}

Conflict of interest The authors declare that they have no conflict of interest.

Open Access This article is licensed under a Creative Commons Attribution 4.0 International License, which permits use, sharing, adaptation, distribution and reproduction in any medium or format, as long as you give appropriate credit to the original author(s) and the source, provide a link to the Creative Commons licence, and indicate if changes were made. The images or other third party material in this article are included in the article's Creative Commons licence, unless indicated otherwise in a 
credit line to the material. If material is not included in the article's Creative Commons licence and your intended use is not permitted by statutory regulation or exceeds the permitted use, you will need to obtain permission directly from the copyright holder. To view a copy of this licence, visit http://creativecommons.org/licenses/by/4.0/.

\section{References}

Beltrami H, Gosselin C, Mareschal JC (2003) Ground surface temperatures in Canada: spatial and temporal variability. Geophys Res Lett 30(10):1499. https://doi.org/10.1029/2003GL017144

Beltrami H, Ferguson G, Harris RN (2005) Long-term tracking of climate change by underground temperatures. Geophys Res Lett 32: L19707. https://doi.org/10.1029/2005GL023714

Beltrami H, Bourlon E, Kellman L, Gonzalez-Rouco JF (2006) Spatial pattern of ground heat gain in the Northern Hemisphere. Geophys Res Lett 33:L06717. https://doi.org/10.1029/2006GL025676

Cao LJ, Zhu YN, Tang GL, Yuan F, Yan ZW (2016) Climatic warming in China according to a homogenized data set from 2419 stations. Int J Climatol 36:4384-4392

Ding YH, Sun Y, Wang ZY, Zhu YX, Song YF (2009) Inter-decadal variation of the summer precipitation in China and its association with decreasing Asian summer monsoon part II: possible causes. Int J Climatol 29(13):1926-1944

Ding YH, Liu YJ, Liang SJ, Ma XQ, Zhang YX, Si D, Liang P, Song YF, Zhang J (2014) Interdecadal variability of the East Asian winter monsoon and its possible links to global climate change. Acta Meteorol Sin 72(5):835-852 (in Chinese)

Fan X (2009) Impacts of soil heating condition on precipitation simulations in the Weather Research and Forecasting Model. Mon Wea Rev 137:2263-2285

Hu Q, Feng S (2004a) Why has the land memory changed? J Clim 17: 3236-3243

Hu Q, Feng S (2004b) A role of the soil enthalpy in land memory. J Clim 17:3633-3643

Kosaka Y, Xie SP (2013) Recent global-warming hiatus tied to equatorial Pacific surface cooling. Nature 501(7467):403-407

Liao YM, Chen D, Liu QF (2019) The spatiotemporal characteristics and long-term trends of surface-air temperatures difference in China. Clim Chang Res 15(4):374-384 (in Chinese)

Liu Y, Avissar R (1999) A study of persistence in the land-atmosphere system using a general circulation model and observations. J Clim 12(8):2139-2153

Maruyama F (2019) Influence of the Atlantic Multidecadal Oscillation and the Pacific Decadal Oscillation on global temperature by wavelet-based multifractal analysis. J Geosci Environ Prot 7:105117. https://doi.org/10.4236/gep.2019.78008

Roy S, Chapman DS (2012) Borehole temperatures and climate change: ground temperature change in south India over the past two centuries. J Geophys Res 117:D11105. https://doi.org/10.1029/ 2011JD017224

Sugihara G, May R, Ye H, Hsieh CH, Deyle E, Fogarty M, Munch S (2012) Detecting causality in complex ecosystems. Science 338(6106):496-500. https://doi.org/10.1126/science.1227079
Tomé AR, Miranda PMA (2004) Piecewise linear fitting and trend changing points of climate parameters. Geophys Res Let 31:L02207. https://doi.org/10.1029/2003GL019100

Wang Y, Chen W, Zhang J, Nath D (2013) Relationship between soil temperature in May over Northwest China and the East Asian summer monsoon precipitation. Acta Meteorol Sin 27(5):716-724

Wang JL, Pan ZH, Han GL, Cheng L, Dong ZQ, Zhang JT, Pan YY, Huang L, Zhao H, Fan DL, Wu D (2016) Variation in ground temperature at a depth of $0 \mathrm{~cm}$ and the relationship with air temperature in China from 1961 to 2010. Resour Sci 38(9):1733-1741 (in Chinese)

Wang YJ, Hu ZZ, Yan F (2017) Spatiotemporal variations of differences between surface air and ground temperatures in China. J Geophys Res Atmos 122:7990-7999. https://doi.org/10.1002/2016JD026110

Woodbury AD, Bhuiyan AKMH, Hanesiak J, Akinremi OO (2009) Observations of northern latitude ground-surface and surface-air temperatures. Geophys Res Lett 36:L07703. https://doi.org/10. 1029/2009GL037400

$\mathrm{Xu}$ WH, Sun CH, Zuo JQ, Ma ZG, Li WJ, Yang S (2019) Homogenization of monthly ground surface temperature in China during 1961-2016 and performances of GLDAS reanalysis products. J Clim 32:1121-1135

Yang S, Li QX (2014) Improvement in homogeneity analysis method and update of China precipitation data. Clim Chang Res 14(4):276-281 (in Chinese)

Yang K, Zhang JY (2016) Spatiotemporal characteristics of soil temperature memory in China from observation. Theor Appl Climatol 126: 739-749

Ye DZ, Gao YX. 1979. The meteorology of Tibet plateau. China Meteorological Press: Beijing, 278pp (in Chinese)

Zhang RH, Levitus S. 1997. Structure and cycle of decadal variability of upper-ocean temperature in the North Pacific. J Clim. 10: $710 \sim 727$

Zhang Y, Chen W, Smith SL, Riseborough DW, Cihlar J (2005) Soil temperature in Canada during the twentieth century: complex responses to atmospheric climate change. J Geophys Res 110: D03112. https://doi.org/10.1029/2004JD004910

Zhou LT (2009) Difference in the interdecadal variability of spring and summer sensible heat fluxes over Northwest China. Atmos Ocean Sci Lett 2(2):119-123

Zhou LT, Du ZC (2016) Regional differences in the surface energy budget over China: an evaluation of a selection of CMIP5 models. Theor Appl Climatol 124:241-266

Zhou LT, Huang RH (2014) Regional differences in surface sensible and latent heat fluxes in China. Theor Appl Climatol 116:625-637

Zhou LT, Huang RH (2010a) The interdecadal variability of summer rainfall in Northwest China and its possible causes. Int J Climatol 30(4):549-557

Zhou LT, Huang RH (2010b) An assessment of the quality of surface sensible heat flux derived from reanalysis data through comparison with station observations in Northwest China. Adv Atmos Sci 27(3): 500-512

Zhu Y, Wang HJ, Ma JH, Wang T, Sun JQ (2015) Contribution of the phase transition of Pacific Decadal Oscillation to the late 1990s' shift in East China summer rainfall. J Geophys Res Atomos 120: 8817-8827. https://doi.org/10.1002/2015JD023545

Publisher's note Springer Nature remains neutral with regard to jurisdictional claims in published maps and institutional affiliations. 